Awards are made to surgeons of unique promise who have been regarded as having the potential for later international thoracic surgical leadership. Since the inception of the Graham Fellowship, 54 young surgeons from 27 countries have been named for the Fellowship.

The Fellowship provides a stipend of $\$ 75,000$, a major portion of which is intended for travel expenses incurred when visiting other medical centers. The Fellowship also provides two round-trip coach air fares from the recipient's country to his/her primary center. The dates of the beginning and ending of the Fellowship year should be scheduled to coincide with the Annual Meetings of The American Association for Thoracic Surgery. The Fellow will be introduced at the May 2007 meeting, which will take place at the Washington DC Convention Center in Washington, DC, May 5-9. The Fellow will be expected to provide a written summary of his/her year's experience to the membership prior to its 2008 Annual Meeting, which will take place at the San Diego Convention Center in San Diego, California, May 10-14.

The Fellow should become involved predominantly with observation, consultation, teaching and research at a variety of thoracic surgical training centers during the twelve months. Patient contact will be determined by the sponsoring surgeon and will conform to the regulations and licensing requirements of the state, province, or country in which he/she is studying.

A candidate should have completed his/her formal training in general surgery and in thoracic and cardiovascular surgery, but he/she should not have reached a senior position. Candidates must be sufficiently proficient in English to realize the full benefits of the fellowship. Candidate should not have had extensive clinical training in North America prior to making application, and should be planning to return to their native country following the completion of their fellowship. "Extensive" clinical training shall mean any period of clinical training which exceeds a total of six months in duration.

The online application submission site was available beginning in March 2006 at www.aats.org. All applications must have been submitted electronically via the online application submission site no later than July 1. The selected candidate was notified by November 1 .

\section{Resident Traveling Fellowship, 2006-2007}

$\mathrm{T}$ The American Association for Thoracic Surgery announces the Resident Traveling Fellowship, a program established to broaden the educational experience of residents in their final year of an approved cardiothoracic surgical training program by providing an opportunity to spend up to two weeks at one or more institutions other than their home institution.

A grant of $\$ 5,000$ will be provided to successful applicants to underwrite their travel and living expenses incurred during up to two weeks of training at one or more host institutions. The funds are also intended to provide for roundtrip travel and four nights' accommodations at the annual meeting of the Association scheduled for May 5-9, 2007 in Washington DC. The fellowship must be completed prior to March 31, 2007.

Applicants must have the approval of their home and prospective host institutions. Candidates must submit an online AATS application and include a one-page outline of what they hope to accomplish during their training. Additionally, award recipients must agree to submit a summary report to the membership of the association within thirty days after the completion of their training.

The candidate must be a North American resident in his or her final year (during 2006-07) of an approved cardiothoracic surgical training program.
Applications must have been completed and submitted online at www.aats.org by July 1. The selected candidates were notified by September 30 to accommodate travel between October 1, 2006 and March 31, 2007.

\section{Second Dwight Harken Research Scholarship, 2007-2009}

$\mathrm{T}$ The American Association for Thoracic Surgery announces the Second Dwight Harken Research Scholarship to provide an opportunity for research, training and experience for North American surgeons committed to pursuing an academic career in cardiothoracic surgery. The scholarship will be funded by the Association and administered by the Graham Education and Research Foundation.

The research program must be undertaken within the first three years after completion of an approved cardiothoracic residency. Applications for the scholarship may be submitted during the candidate's final year of cardiothoracic residency or during his or her first two years in an academic position. The duration of the scholarship is to be two years.

The yearly stipend shall be $\$ 75,000$ paid to the host institution. In addition, a grant of $\$ 5,000$ per year shall be made for support of research supplies, travel, and other legitimate academic expenses of the scholar. The application consists of three components:

1. The candidate must submit a proposal for the research to be undertaken and a statement of career plans and how the research activity will relate to the candidate's academic career.

2. The director of the laboratory in the institution at which the research will be performed shall submit an endorsement of the proposal and indicate the facilities and degree of support available for the candidate's research.

3. The chairman of the candidate's department shall submit his or her endorsement of the proposal and indicate the willingness of the institution to provide an academic appointment for the candidate upon completion of the scholarship.

The application and its components must have been submitted online at www.aats.org by July 1. Announcement of the award was made by the president of the American Association for Thoracic Surgery December 15. The scholarship will begin July 1, 2007. Following completion of the two-year program, the scholar shall submit a written report of his/her research activities to the membership of the Association.

\title{
Announcement of 2007 Annual Meeting
}

$\mathrm{T}$ The Thirty-third Annual Meeting of the Western Thoracic Surgical Association will be held June 27-30, 2007 at the Hyatt Regency Tamaya in Santa Ana Pueblo, New Mexico. The scientific sessions are open to all duly qualified physicians. Participation in other Association activities for members, invited guests, and program participants requires payment of a social registration fee.

\section{Requests for Meeting Information}

Meeting preregistration and hotel registration forms were available after January 2007 from: 